Check for updates

Cite this: RSC Adv., 2019, 9, 23465

Received 19th May 2019

Accepted 1st July 2019

DOI: $10.1039 / c 9 r a 03762 d$

rsc.li/rsc-advances

\title{
A microcapsule oil dispersion for the controlled release of 1-methylcyclopropene in an open environment $\dagger$
}

\begin{abstract}
Xinyu Guo, ${ }^{a}$ Rui Zhao, ${ }^{a}$ Jia Zhang, ${ }^{b}$ Ying-Jie Du, ${ }^{c}$ Lu-Guang Yang, ${ }^{c}$ Luoyun Chen, ${ }^{a}$ Sen Pang, ${ }^{a}$ Yong $\mathrm{Xu}{ }^{a}$ Zhenhua Zhang ${ }^{\star a}$ and Xuemin Wu (D) *a

1-Methylcyclopropene (1-MCP) is an important gaseous plant growth regulator. For its application as a gaseous pesticide, the plants with 1-MCP $\alpha$-cyclodextrin microcapsule granules need to be enclosed in a sealed chamber. To provide a new spray formulation of 1-MCP for open environment application, herein, a novel 1-MCP microcapsule oil dispersion (1-MCP/MCOD) was prepared and characterized. It was found that 1-MCP could stay at higher concentrations for more than 36 hours during the controlled release experiment, and the SEM experiment showed good deposition of the 1-MCP/MCOD spray solution. In addition, the apple harvest application experiments showed that 1-MCP/MCOD could effectively prevent fruit drop at $3 \mu \mathrm{L} \mathrm{L}^{-1}$ in an open environment. These results not only supply a new 1MCP/MCOD kind of formulation for the flexible application of the 1-MCP gas in an open environment, but also show that this microcapsule oil dispersion formulation has significant potential in gaseous pesticide applications.
\end{abstract}

\section{Introduction}

As a plant growth regulator, 1-methylcyclopropene (1-MCP) is an effectively irreversible ethylene action inhibitor in fruits, vegetables, flowers and crops. ${ }^{1-7}$ In the gaseous state, 1-MCP acts as a highly efficient and non-toxic pesticide. ${ }^{\mathbf{8} 9}$ However, 1MCP is chemically unstable under normal environmental conditions and presents an explosive hazard when compressed. ${ }^{\mathbf{1 0}}$ Microcapsule formulations in biodegradable carriers, such as starch, have been widely developed and used in agriculture to improve pesticide utilization and reduce environmental pollution. ${ }^{1{ }^{1-13}}$ Hence, the commercial formulation of 1-MCP constitutes microcapsule granules with $\alpha$-cyclodextrin, called 1-MCP microcapsule granules (1-MCP/MCG), ${ }^{\mathbf{1 4}, 15}$ which can release the 1-MCP gas as soon as they come in contact with water. ${ }^{16}$ This formulation has been well applied in maintaining the quality of fruit and vegetables, such as apples, ${ }^{\mathbf{1 7}, \mathbf{1 8}}$ kiwifruits, ${ }^{19,20}$ plums, ${ }^{21,22}$ bananas, ${ }^{23,24}$ avocados, ${ }^{25,26}$ and tomatoes, ${ }^{27,28}$ by delaying senescence. In addition to maintaining the quality of fruits and vegetables during storage, many studies have shown that 1-MCP can prevent fruit drop ${ }^{29,30}$ and alleviate

${ }^{a}$ College of Science, China Agricultural University, Beijing 100193, China. E-mail: zhangzhh@cau.edu.cn; wuxuemin@cau.edu.cn; Tel: +8601062734645

${ }^{b}$ The Institute for the Control of Agrochemicals, Ministry of Agriculture and Rural Affairs of the People's Republic of China, Beijing, 100125, China ${ }^{c}$ Laizhou Agricultural and Rural Bureau, Laizhou, Shandong, 261400, China

$\dagger$ Electronic supplementary information (ESI) available. See DOI: 10.1039/c9ra03762d the detrimental effect of ethylene on the crops. ${ }^{31,32}$ For example, 1-MCP could effectively reduce pre-harvest fruit drop, maintain the firmness, soluble solids and reduce the production of endogenous ethylene of apples. ${ }^{33,34}$ Moreover, 1-MCP has marked effects on increasing the spikelet fertility and harvest index of the hybrid rice cultivars. ${ }^{7}$ All these applications require the controlled release of 1-MCP in an open environment such as fields and orchards. ${ }^{35-38}$ However, the rapid release of 1-MCP/ MCG limits its usage to only in an airtight environment.

Based on the use of oil to achieve a controlled contact of 1MCP/MCG with water, several ways of applying 1-MCP in an open environment have been reported; one way is mixing 1MCP/MCG with special spray oil, a surfactant and water in tailored equipment before its application in the field. ${ }^{39}$ However, the release performance of 1-MCP depends critically on the addition order, mixing time, and usage time. This application process is inconvenient and difficult to practice for farmers and gardeners. Another way is to make 1-MCP/MCG as a liquid-base formulation and dilute it with water before spraying it in the field. A patent has mentioned an example of a water-in-oil-in-water double emulsion formulation, where 1MCP/MCG is present in a mixture of oil, surfactant and water. ${ }^{40}$ However, no particular studies have been reported on its release data and field effects in details. The oil-water system of 1-MCP/MCG is difficult and has high-cost of processing, and the release of 1-MCP cannot be totally prevented during storage when the formulation of $1-\mathrm{MCP} / \mathrm{MCG}$ is a water-containing system. In addition to the abovementioned two ways, the oil 
dispersion (OD) formulation is a potential approach to process 1-MCP/MCG.

With the development of oil medium, emulsifier, dispersant, and other additives, OD has been a safe, environmentally friendly and effective formulation for the application of poorwater-stability pesticides, improving the spreading ability and permeability of pesticides, especially for aerial crop protection. ${ }^{41-44}$ Herein, the 1-MCP microcapsule oil dispersion (1MCP/MCOD) formulation could make 1-MCP/MCG more stable and control its release when diluted with water. In addition, 1-MCP/MCOD would be easier to emulsify and deposit on plant tissues; this would make the 1-MCP spray more convenient and effective in an open environment (Fig. 1). However, there are two major challenges in the development of 1-MCP/MCOD: one is the thermodynamically/dynamically unstable solid-liquid dispersed suspension system, which has easy flocculation/caking characters, ${ }^{45}$ and second is the difficultly in managing a controlled contact of 1-MCP/MCG with water after dilution. In this study, a well 1-MCP/MCOD spray formulation was prepared and characterized, and the preharvest applications of the two apple cultivars were also studied.

\section{Experimental}

\subsection{Materials}

1-MCP/MCG (the content of 1-MCP was 3.3\%) was prepared as described in the ESI. $\dagger$ Mineral oil, purity $\geq 99.0 \%$ (content of non-sulfonate), was purchased from H\&R China (Ningbo) Co., Ltd. (China). Methyl ester oil, purity $\geq 98.0 \%$ (content of methyl palmitate and methyl stearate), was purchased from P\&G Chemicals (USA). Vegetable oil, purity $\geq 95.0 \%$ (content of terpene, resin acid, and fatty acid monoalkyl esters) was provided by Fujian Lord Biotechnology Co., Ltd. (China). The technical-grade nonionic emulsifier was nonylphenol decaethoxylate $\quad\left[\mathrm{C}_{9} \mathrm{H}_{19} \mathrm{C}_{6} \mathrm{H}_{4}\left(\mathrm{OCH}_{2} \mathrm{CH}_{2}\right)_{10} \mathrm{OH}\right] \quad(\mathrm{NP}-10) . \quad$ The technical-grade anionic emulsifier was calcium dodecylbenzenesulfonate (Ca-DBS). The technical-grade non-ionic and anionic complex emulsifiers were NP-10/Ca-DBS (w/w, $2: 1$ ), fatty alcohol polyoxyethylene ether $\left[\mathrm{C}_{12} \mathrm{H}_{25} \mathrm{O}\left(\mathrm{CH}_{2} \mathrm{CH}_{2} \mathrm{O}\right)_{3} \mathrm{H}\right]$ (AEO-3) and Ca-DBS (AEO-3/Ca-DBS) (w/w, $2: 1$ ). The emulsifiers were provided by Nantong Deyi Chemical Co., Ltd. (China). Further, the technical-grade non-ionic dispersant polyisobutylene succinimides (PIBSI) was obtained from Jinzhou Snda Chemical Co., Ltd. (China), and polyalkenyl polyethylene glycol alkyd copolymer (PPGAC) was obtained from Croda International Plc. (UK). As a technical-grade anionic dispersant, sulfosuccinate (SSU) was obtained from SK Agro Think (Shanghai) Corp. Co., Ltd. (China). Standard Water (342 ppm hardness, $\mathrm{Ca}^{2+}: \mathrm{Mg}^{2+}=4: 1$ ) and deionized water were obtained from the College of Science, China Agricultural University.

\subsection{Plant material}

"Jinhong" and "Longfeng" (Malus $\times$ domestica Borkh.) apple fruit growing in the Bai'an Yuan orchard at Huang'antuo village, Qingshui Town, Mentougou District, Beijing, China, were used as plant materials. The selected fruit trees were basically the same in size. They were grown under similar climatic conditions and received common cultural practices.

\subsection{Preparation of 1-MCP/MCOD}

The 1-MCP/MCOD was prepared by screening different types of oil media, emulsifiers and dispersants. It was processed by the wet ultrafine grinding method using a sand mill (TaizhouJiangyan Deli Motor Co., Ltd., China). The sand mill was rotated at 1400 revolutions per minute for 1 hour.

The appropriate oil medium was screened by detecting whether 1-MCP could be released in the carrier or not. Briefly, $4.0 \mathrm{~mL}$ of the oil medium was added to a headspace bottle. Then, $20.0 \mathrm{mg}$ of 1-MCP/MCG was added to the same bottle, and the bottle was sealed. Next, the headspace bottle was placed on a mechanical shaker followed by mixing for 10 minutes. Finally, the gas of the headspace was measured by the GC-2010 Plus gas chromatograph (SHIMADZU, Japan) with the Rtx-5 column (30 $\mathrm{m}, 0.25 \mathrm{~mm}$ ID, $0.25 \mu \mathrm{m}$; Restek, USA). The injection pot and the detector temperatures were set at 150 and $200{ }^{\circ} \mathrm{C}$, respectively. The column temperature was $150{ }^{\circ} \mathrm{C}$, with the hold time of $3 \mathrm{~min}$, and the total analysis time was $3 \mathrm{~min}$.

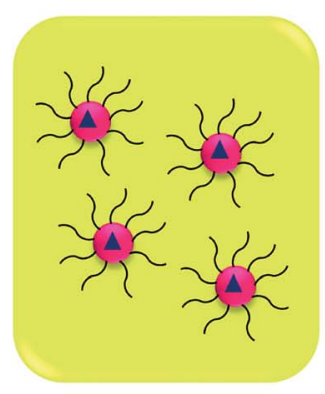

1-MCP/MCOD

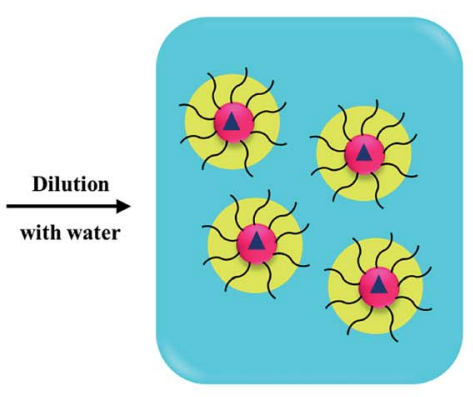

Spray solution

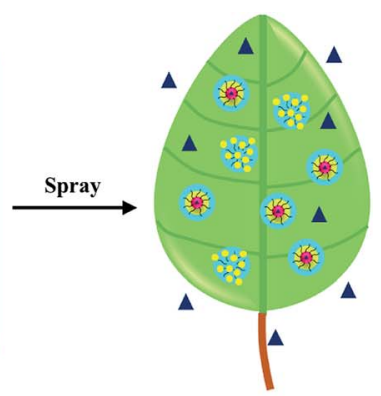

The plant tissues

Fig. 1 The formulation of 1-MCP/MCOD and the controlled release process. 
The appropriate emulsifier was selected by testing the emulsion stability of the oil medium and emulsifiers. Briefly, $4.0 \mathrm{~mL}$ of emulsifier was added to $16.0 \mathrm{~mL}$ of an oil medium and mixed well. Then, $0.5 \mathrm{~mL}$ of the mixture solution was added to $99.5 \mathrm{~mL}$ of standard water in a measuring cylinder $(100 \mathrm{~mL})$. The measuring cylinder was inverted 10 times to obtain a $100 \mathrm{~mL}$ aqueous emulsion. The emulsion stability was evaluated after the measuring cylinder was kept undisturbed in a constant temperature bath at $30{ }^{\circ} \mathrm{C} \pm 2{ }^{\circ} \mathrm{C}$ for $1 \mathrm{~h}$.

The appropriate dispersant was selected by testing the physical stability of 1-MCP/MCOD formulations that could be observed by the multiple light scattering technique using a commercial instrument (Turbiscan Lab® Expert, Formulaction, France) and appearance changes during thermal storage. 1-MCP/ MCOD was processed with the appropriate oil medium, the appropriate emulsifier and different dispersants. Briefly, $24.3 \mathrm{~g}$ of 1-MCP/MCG, $20.0 \mathrm{~g}$ of emulsifier, $3.0 \mathrm{~g}$ of dispersant and $55.7 \mathrm{~g}$ of oil medium were put in a sand grinding bucket and mixed for 2 hours. Then, $20 \mathrm{~mL}$ of the 1-MCP/MCOD was placed without dilution in a glass vial with a height of approximately $42 \mathrm{~mm}$ and monitored by a commercial instrument every 1 hour for $26 \mathrm{~h}$ at $25{ }^{\circ} \mathrm{C}^{46}$ Another $50 \mathrm{~mL}$ of $1-\mathrm{MCP} / \mathrm{MCOD}$ was monitored by observing changes in the appearance during thermal storage, where the samples were stored at $54 \pm 2{ }^{\circ} \mathrm{C}$ for 14 days; for carrying out this experiment, the Collaborative International Pesticides Analytical Council (CIPAC) methods, which were conducted in accordance with FAO and WHO standards, were used. ${ }^{47}$

\subsection{Quality indicators of the most stable 1-MCP/MCOD}

The quality indicators, including appearance, content of 1-MCP, particle size, density, viscosity, $\mathrm{pH}$ value, moisture, emulsion stability, and storage stability, of the most stable 1-MCP/MCOD formulation prepared in this study were evaluated using the Collaborative International Pesticides Analytical Council (CIPAC) methods, which were conducted in accordance with the FAO and WHO standards.

The appearance was observed by transferring approximately $50 \mathrm{~mL}$ of the freshly prepared 1-MCP/MCOD in a glass tube.

The qualitative analysis of 1-MCP was conducted using the GCMS-QP2010 SE gas chromatograph-mass spectrometer (SHIMADZU, Japan) with the Rtx-5Sil MS column (30 m, $0.25 \mathrm{~mm}$ ID, $0.25 \mu \mathrm{m}$; Restek, USA). The injection pot and the detector temperatures were set at 150 and $200{ }^{\circ} \mathrm{C}$, respectively. The column temperature was $150{ }^{\circ} \mathrm{C}$, with the hold time of $3 \mathrm{~min}$, and the total analysis time was $3 \mathrm{~min}$. The quantitative analysis of 1MCP was conducted using the GC-2010 Plus gas chromatograph. The quantification of 1-MCP was accomplished using an external standard method. The isobutylene gas standard of $40 \mathrm{~g} \mathrm{~m}^{-3}$ concentration was used. It was speculated that the quantities of 1-MCP had a response factor similar to that of isobutylene.

The particle size $D_{50}$ and particle size Span were analyzed by the Bettersize 2000 laser particle size analyzer (Bettersize Instruments Ltd., Liaoning, China).

The density was analyzed using the ALC-210.3 electronic balance (Sartorius, Germany) and a volumetric flask.
The viscosity was measured by the NDJ-1 Rotary Viscometer (Shanghai Changji Geological Instrument Co. Ltd., China).

The $\mathrm{pH}$ value was analyzed by the FiveEasy Plus $\mathrm{pH}$ meter (Mettler Toledo Instruments (Shanghai) Co., Ltd., China).

The moisture was analyzed by the $870 \mathrm{KF}$ Titrino plus moisture teller (Metrohm, Switzerland).

The storage stability included two aspects: storage at $0 \pm 2{ }^{\circ} \mathrm{C}$ for 7 days and storage at $54 \pm 2{ }^{\circ} \mathrm{C}$ for 14 days, and the formulations were analyzed based on the abovementioned clauses.

\subsection{Release experiment}

The 1-MCP/MCOD was diluted with deionized water of different dilution factors $(10,20$ and 30). The dilution factor was calculated by the ratio of the total weight of 1-MCP/MCOD and water to the weight of 1-MCP/MCOD.

On the one hand, the initial release of the solutions was tested in the headspace bottle in two minutes. Briefly, $100.0 \mathrm{mg}$ of the 1-MCP/MCOD was added to the headspace bottle. Then, a certain quality of deionized water was added to the same bottle, and the bottle was sealed. Next, the headspace bottle was shaken for mixing the contents thoroughly. Finally, the gas of the headspace was measured by GC after two minutes.

On the other hand, the release of the solutions after spraying at a certain time was tested in the airtight box with a volume of $2.75 \mathrm{~L}$. Briefly, a certain weight of the 1-MCP/ MCOD solutions was sprayed in the airtight box. The gas in the airtight box was extracted at appropriate intervals, and the concentration of 1-MCP was measured and monitored by GC.

\subsection{Surface morphologies of the spray solution deposition on two apple cultivars}

Scanning electron microscopy (SEM, S-4800, Hitachi Ltd., Tokyo, Japan) was employed for the morphological examination of the spray solution deposited on the apple tissues. The peel, leaves and the branches of "Jinhong" and "Longfeng" were sprayed with a certain concentration of the 1-MCP/MCOD solution. The deionized water spray treatment was used as a control. After the solvent on the tissues evaporated, the tissues were freeze-dried. Then, all the samples were pre-treated by spray-gold before observation using SEM.

\subsection{Application on two apple cultivars}

The two apple cultivars "Jinhong" and "Longfeng" were sprayed with 1-MCP/MCOD seven days before the anticipated harvest date. The ground under the trees was cleaned of fruit and leaves just before the treatments. The fruit trees were treated in the airtight environment using the plastic tents $(3 \mathrm{~m}$ $\times 3 \mathrm{~m} \times 4 \mathrm{~m}=36 \mathrm{~m}^{3}$ ) or in the open environment. The spray treatments were applied with a hand sprayer. The specific concentrations of 1-MCP used are shown in Table 1. Each treatment started at 17:00 pm and ended at 5:00 am the next morning. The plastic tents were removed, and the airtight treatment time was 12 hours. Fruit drop number was detected at appropriate intervals, until the day when the fruits remaining on the trees were harvested, and the cumulative 
Table 1 Test arrangements for preharvest application of the two apple cultivars

\begin{tabular}{llcc}
\hline Cultivars & Items & Concentrations $\left(\mu \mathrm{L} \mathrm{L}^{-1}\right)$ & Treatment methods \\
\hline "Jinhong" & 1 & $3.0^{a}$ & OD, airtight spray \\
& 2 & $30.0^{a}$ & OD, airtight spray \\
& 3 & $3.0^{b}$ & OD, open spray \\
& 4 & $30.0^{b}$ & OD, open spray \\
CK1 & 0 & Untreated contrast \\
& CK2 & 0 & Untreated contrast \\
& 1 & $0.3^{a}$ & OD, airtight spray \\
& 2 & $1.0^{a}$ & OD, airtight spray \\
& 3 & $3.0^{a}$ & OD, airtight spray \\
& 4 & $0.3^{b}$ & OD, open spray \\
& 5 & $1.0^{b}$ & OD, open spray \\
& 6 & $3.0^{b}$ & OD, open spray \\
& 7 & $1.0^{c}$ & MCG, airtight fumigation \\
& CK1 & 0 & Untreated contrast \\
CK2 & 0 & Untreated contrast
\end{tabular}

${ }^{a}$ The fruit trees were treated by spraying in the airtight environment created by using plastic tents $\left(3 \mathrm{~m} \times 3 \mathrm{~m} \times 4 \mathrm{~m}=36 \mathrm{~m}^{3}\right) .{ }^{b}$ The fruit trees were treated by spraying in the open environment, with the used dosages being the same as in the airtight environment. ${ }^{c}$ The fruit trees were treated by fumigation in the airtight environment created using plastic tents $\left(3 \mathrm{~m} \times 3 \mathrm{~m} \times 4 \mathrm{~m}=36 \mathrm{~m}^{3}\right)$.

drop was calculated. For "Jinhong", the final harvest date was August 23, 2018. For "Longfeng", the final harvest date was September 21, 2018.

\section{Results and discussion}

\subsection{Chemical stability with oil media}

Table 2 shows the results of the 1-MCP/MCG release test in three kinds of oil media, and it can be found that

1-MCP/MCG can exist stably in mineral oil and vegetable oil, in which 1-MCP cannot be detected by GC. However, 1-MCP was released in methyl ester oil. Therefore, mineral oil and vegetable oil were selected for the next test.

\subsection{Emulsification with emulsifiers}

The emulsification results of the emulsifier screening tests for mineral oil and vegetable oil are shown in Fig. 2 and Table 3. Mineral oil with AEO-3/Ca-DBS was an optimum combination, in which the emulsion showed no top cream and no sediment (Fig. 2b); on the other hand, the emulsion of vegetable oil with NP-10 showed a little top cream and no sediment (Fig. 2h). The other combinations were poor. Therefore, the combination of mineral oil with AEO-3/Ca-DBS was chosen for the next experiment of selection of dispersants.

Table 2 The stability of 1-MCP/MCG in oil media

\begin{tabular}{lll}
\hline Items & 1-MCP peak area & Results \\
\hline Mineral oil & 0 & Stable \\
Methyl ester oil & 3299 & Release \\
Vegetable oil & 0 & Stable
\end{tabular}

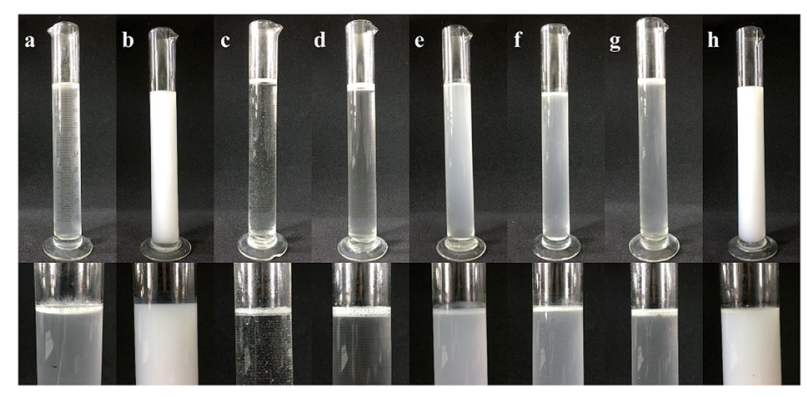

Fig. 2 Stability of the emulsion prepared using different emulsifiers in oil media (for mineral oil with: (a) NP-10/Ca-DBS, (b) AEO-3/Ca-DBS, (c) Ca-DBS, and (d) NP-10; for vegetable oil with: (e) NP-10/Ca-DBS, (f) AEO-3/Ca-DBS, (g) Ca-DBS, and (h) NP-10).

\subsection{Physical stability with dispersants}

The 1-MCP/MCOD formulations were prepared with 1-MCP/ MCG, mineral oil, AEO-3/Ca-DBS and different dispersants by wet ultrafine grinding. The physical stability results are shown in Fig. 3 and 4 and Table 4 . The main instability of the preparation was due to particle aggregation, coalescence and flocculation in the sample. As observed through analysis using the multiple light scattering technique, 1-MCP/MCOD prepared using PPGAC and PIBS showed rapid sedimentation; an increase in backscattering at the bottom $(0-10 \mathrm{~mm})$ and a decrease in backscattering in the middle-upper part (10-40 $\mathrm{mm}$ ) could be observed in Fig. 3a and b; in contrast, the SSU system (Fig. 3c) showed a slight change in backscattering in the bottom and middle-upper part (0-40 $\mathrm{mm}$ ) and a slight decrease in backscattering at the top (40-42 $\mathrm{mm}$ ), which exhibited good physical stability. We could also observe from Fig. 4 and Table 4 that the system with SSU had good physical stability. Therefore, the 1-MCP/MCOD with the SSU dispersant was most stable. 
Table 3 Emulsification of different combinations of emulsifiers and oil media

\begin{tabular}{llr}
\hline Items & Mineral Oil & Vegetable oil \\
\hline NP-10/Ca-DBS & Much top cream and no sediment & Much top cream and no sediment \\
AEO-3/Ca-DBS & No top cream and no sediment & Much top cream and no sediment \\
Ca-DBS & No emulsification & Much top cream and no sediment \\
NP-10 & No emulsification & Little top cream and no sediment
\end{tabular}

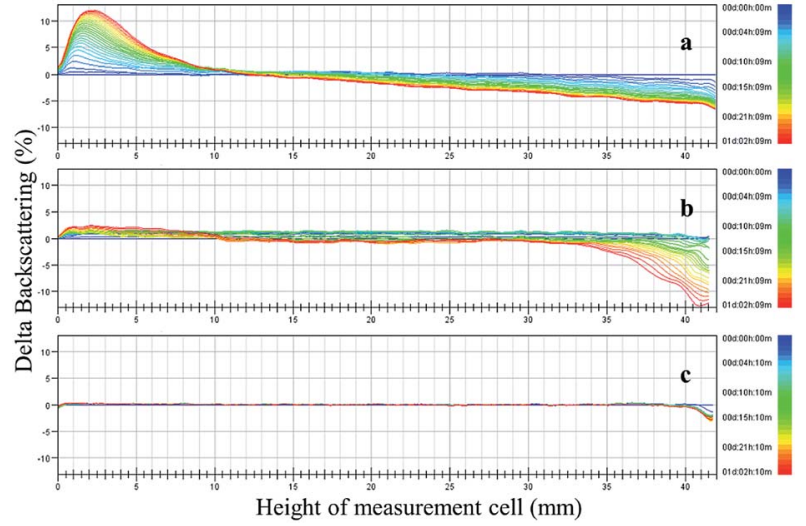

Fig. 3 Changes in backscattering (delta backscattering) as a function of sample height (from 0 to $42 \mathrm{~mm}$ ) and time (from 0:00 to 26:00 h) of the 1-MCP/MCOD prepared using different dispersants ((a) PPGAC, (b) PIBS, and c. SSU). The different colored curves from blue to red in each panel indicate different times from 0:00 to 26:00 $\mathrm{h}$ and the changes in phase separation. For more details, see Fig. S5, S6 and S7.†

\subsection{The evaluation of quality indicators}

Mineral oil as the oil medium, AEO-3/Ca-DBS as the emulsifier, SSU as the dispersant and 1-MCP/MCG were used to prepare 1$\mathrm{MCP} / \mathrm{MCOD}$. The quality indicators of the most stable 1-MCP/ MCOD prepared herein were evaluated, which are shown in Table 5. The GCMS chromatogram and the mass spectra of 1MCP in 1-MCP/MCOD are shown in Fig. 5 and 6, respectively. The mass spectra proved that $1-\mathrm{MCP}$ was present in 1-MCP/ MCOD. The physical and chemical properties of the 1-MCP/ MCOD formulation after and before the storage stability test are shown in Table S2. $\dagger$ The appearance, content of 1-MCP, particle size, density, viscosity, $\mathrm{pH}$ value, moisture, emulsion stability and storage stability could satisfy the application and shelf life requirements of 1-MCP/MCOD.

\subsection{The release results}

The initial release data for different dilution factors $(10,20$ and 30 ) after two minutes in the headspace bottle were $27.7 \%$, $53.1 \%$, and $64.4 \%$, respectively. The results showed that only a small amount 1 -MCP $(27.7 \%)$ was released in the case of the dilution factor 10 in two minutes, whereas a lot of 1-MCP was released in the case of the dilution factors $20(53.1 \%)$ and 30 (64.4\%).

Furthermore, the release results of the diluents after spraying at a certain time in the airtight box are shown in Fig. 7, and the detailed data are presented in Table S $3 \uparrow$ to compare their

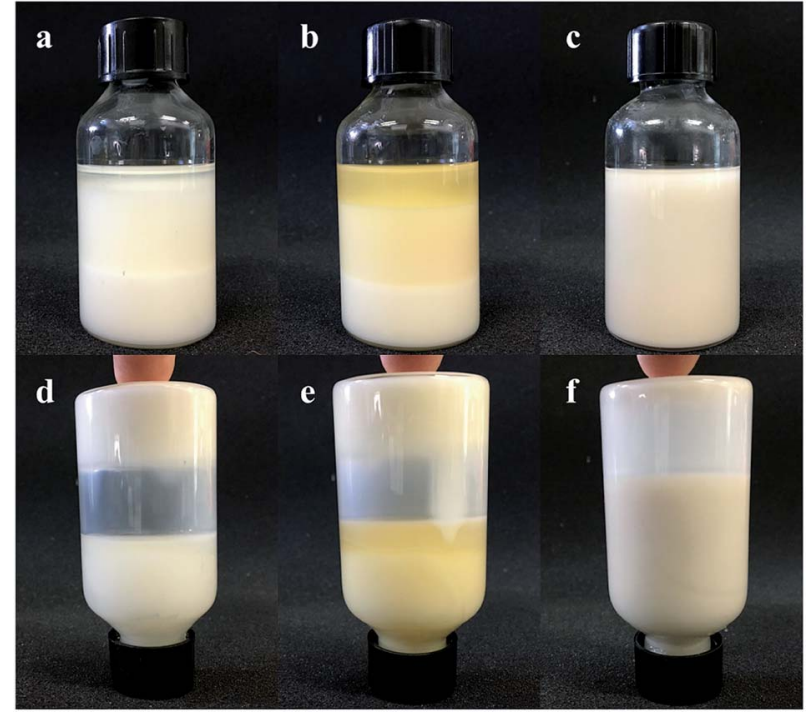

Fig. 4 The appearance of 1-MCP/MCOD prepared using different dispersants after 14 days of storage at $54 \pm 2{ }^{\circ} \mathrm{C}$ ((a) PPGAC, (b) PIBS, (c) SSU, (d) PPGAC, (e) PIBS, and f. SSU).

release behaviors. The relative concentration was calculated by the ratio of the concentration of 1-MCP $(t)$ to the concentration of 1-MCP ( $1 \mathrm{~h})$ in the airtight box. For the dilution factors 20 and 30 , the relative concentration reached a maximum (1.0) in the first hour and then decreased slowly. After 36 hours, the relative concentrations of them were 0.28 and 0.37 . The curves of the dilution factor 20 and 30 were nearly the same, and the decrease in the release time for the dilution factor 20 occurred a little quicker than that for the dilution factor 30. However, for the dilution factor 10 , the relative concentration curve was different. The minimum relative concentration 1.0 was observed in the first hour and increased quickly from $1 \mathrm{~h}$ to $7 \mathrm{~h}$. Then, the increase occurred slowly, and the maximum value of 1.49 was achieved in $20 \mathrm{~h}$. After $20 \mathrm{~h}$, the relative concentration decreased slowly and was maintained at a relatively high level (nearly 1.40).

Table 4 The thermal storage physical stability of 1-MCP/MCOD with different dispersants

\begin{tabular}{ll}
\hline Items & Thermal storage test \\
\hline PIBS & Serious oil perspiring and sediment \\
PPGAC & Serious oil perspiring and sediment \\
SSU & Slight oil perspiring and no sediment
\end{tabular}


Table 5 The results of formulation evaluation

\begin{tabular}{ll}
\hline Evaluation indicators & Results \\
\hline Appearance & White solid-liquid suspension \\
Content of 1-MCP & $0.80 \%$ \\
Particle size (D $\left.{ }_{50}\right)$ & $3.28 \mu \mathrm{m}$ \\
Particle size (Span) & 1.984 \\
Density & $0.9743 \mathrm{~g} \mathrm{~mL}^{-1}$ \\
Viscosity & $320 \mathrm{mPa} \mathrm{s}$ \\
pH (1\%) & 7.08 \\
Moisture & $2.25 \%$ \\
Emulsion stability & Qualified \\
Storage stability & Qualified
\end{tabular}

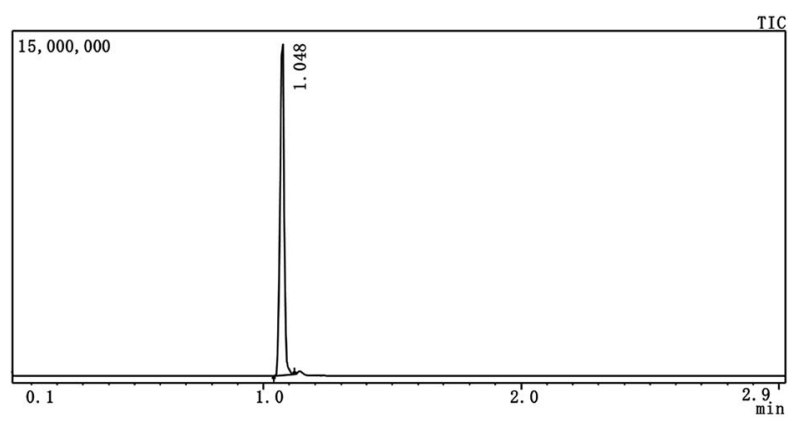

Fig. 5 The GCMS chromatogram of 1-MCP in 1-MCP/MCOD.

\subsection{SEM of the spray solution deposition}

The morphology of the 1-MCP/MCOD spray solution deposition on the two apple cultivars tissues is presented in Fig. 8 and 9. As shown in Fig. 8a, d and Fig. 9a, d, there was nothing on the tissues. In contrast, in Fig. 8e-h and Fig. 9e and d, it could be clearly observed that 1-MCP/MCOD was attached to the surface of the apple peel, upper and lower surfaces of the leaves, and the surface of the branches. Thus, it was proved that 1-MCP/MCOD could effectively adhere to the surface of the sprayed tissues; this provided a possibility for a sustained pesticide effect.

\subsection{Fruit drop on two apple cultivars}

It is always difficult to harvest a lot of apple fruit in a short period of time. Generally, a less than ten percent of the pre-

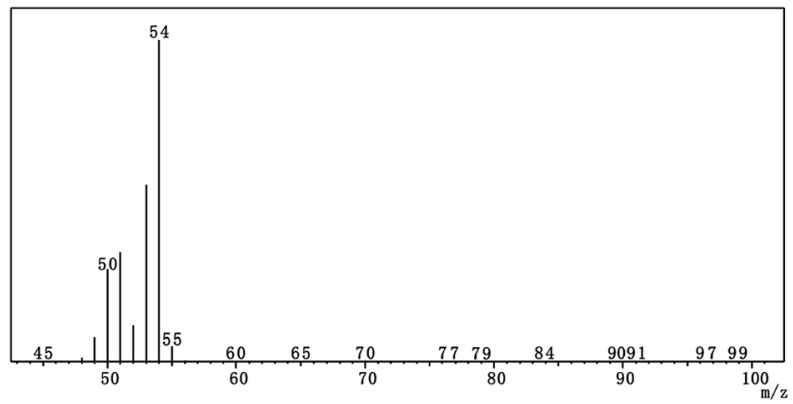

Fig. 6 The GCMS mass spectrogram of 1-MCP in 1-MCP/MCOD.

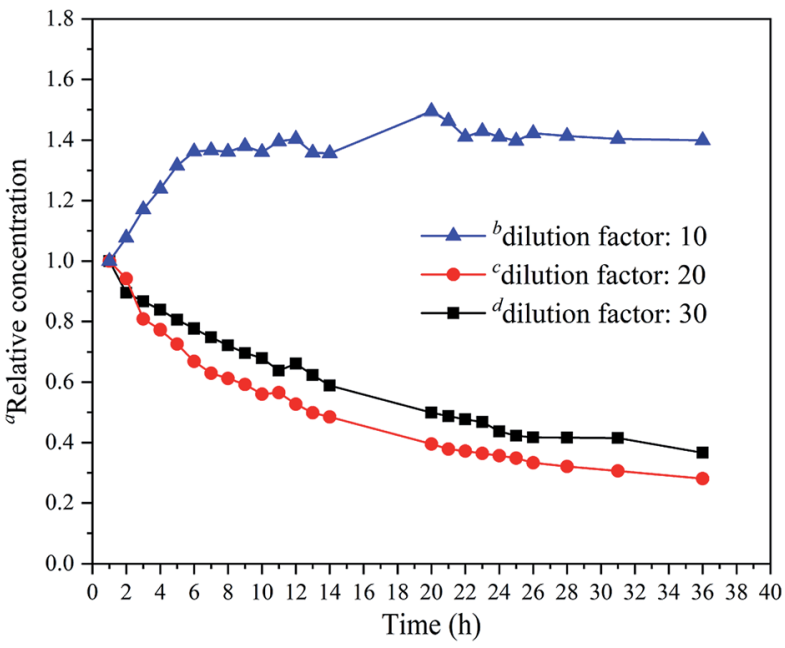

Fig. 7 The relationship between the relative concentration of 1-MCP and the release time in the airtight box. ${ }^{\mathrm{a}}$ The relative concentration $(t)$ $=$ the concentration of 1-MCP $(t) /$ the concentration of 1-MCP $(1 \mathrm{~h})$. ${ }^{\mathrm{b}}(1-\mathrm{MCP} / \mathrm{MCOD}+$ water $) /(1-\mathrm{MCP} / \mathrm{MCOD})$ (weight) $=10 .{ }^{\mathrm{c}}(1-\mathrm{MCP} /$ MCOD + water $) /(1-M C P / M C O D)$ (weight) $=20 .{ }^{d}(1-M C P / M C O D+$ water) $/(1-\mathrm{MCP} / \mathrm{MCOD}$ ) (weight) $=30$. For more details about the relationship between the measured concentrations and the release time see Fig. S8, S9, and S10. $\dagger$

harvest apple fruit drop is acceptable. ${ }^{48}$ In these experiments, the fruit drop was greatly reduced in the cultivars. The results of the pre-harvest application of 1-MCP/MCOD on the apples are shown in Fig. 10. The field images for the end date of the experiments are shown in Fig. 11.

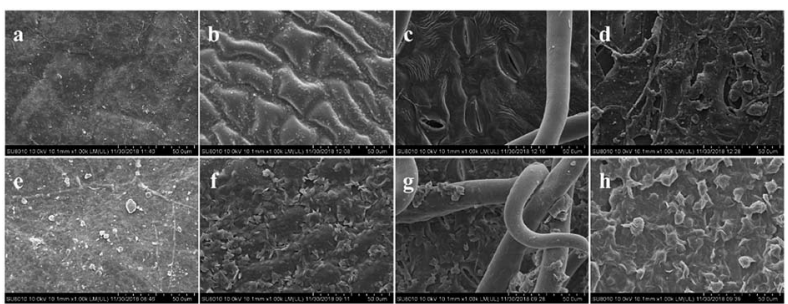

Fig. 8 The SEM images of spray solution deposition on "Jinhong" (for CK: (a) peel surface, (b) upper surface of leaf, (c) lower surface of leaf, (d) branch surface; for 1-MCP/MCOD: (e) peel surface, (f) upper surface of leaf, $(g)$ lower surface of leaf, and (h) branch surface).

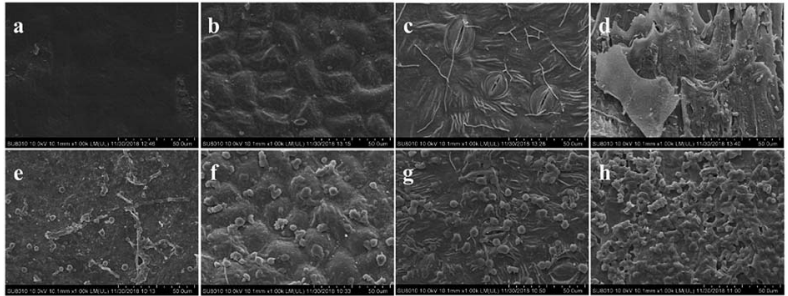

Fig. 9 The SEM images of spray solution deposition on "Longfeng" (for CK: (a) peel surface, (b) upper surface of leaf, (c) lower surface of leaf, (d) branch surface; for 1-MCP/MCOD: (e) peel surface, (f) upper surface of leaf, (g) lower surface of leaf, and (h) branch surface). 

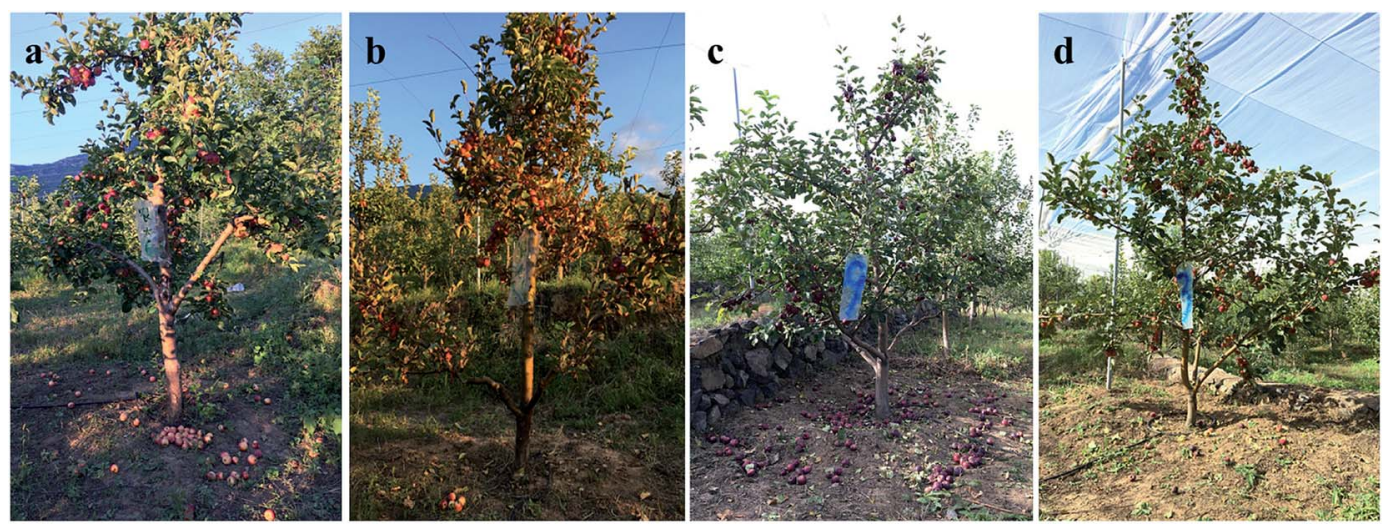

Fig. 10 Days after application and fruit dropping of two apple cultivars ((a) cumulative fruit drop (no. apples per tree) of "Jinhong", (b) cumulative fruit drop (\%) of "Jinhong", (c) cumulative fruit drop (no. apples per tree) of "Longfeng", (d) cumulative fruit drop (\%) of "Longfeng").

For "Jinhong", the effects of 1-MCP/MCOD on fruit drop are shown in Fig. 10a and b, and the data details are provided in Table S4 and S5. $\dagger$ Compared with that of the untreated control, the concentration of $3 \mu \mathrm{L} \mathrm{L}^{-1}$ and $30 \mu \mathrm{L} \mathrm{L}^{-1}$ of 1-MCP/MCOD could effectively prevent fruit drop under both airtight and open conditions. The effect of 1-MCP/MCOD at the low concentration of $3 \mu \mathrm{L} \mathrm{L}^{-1}$ was better than that at the high concentration of $30 \mu \mathrm{L} \mathrm{L}^{-1}$. The effect of 1-MCP/MCOD at low concentrations in an airtight environment was better than that in an open environment. The twelfth day was the harvest day. The order of effectiveness in preventing fruit drop was as follows: airtight $3 \mu \mathrm{L} \mathrm{L}^{-1}>$ open $3 \mu \mathrm{L} \mathrm{L}^{-1}>$ open $30 \mu \mathrm{L} \mathrm{L}^{-1}>$ airtight $30 \mu \mathrm{L} \mathrm{L}^{-1}$. All treatments reduced the "Jinhong" fruit drop. The field images of the end date are shown in Fig. 11a and b. It could be observed that the fruit drop for "Jinhong" treated with airtight $3 \mu \mathrm{L} \mathrm{L}^{-1}$ and open $3 \mu \mathrm{L} \mathrm{L}{ }^{-1}$ was significantly less than that in the untreated case.

Furthermore, the effects of the pre-harvest application of 1MCP/MCOD on "Longfeng" under different low concentration conditions $\left(0.3 \mu \mathrm{L} \mathrm{L}^{-1}, 1 \mu \mathrm{L} \mathrm{L}^{-1}\right.$ and $\left.3 \mu \mathrm{L} \mathrm{L}^{-1}\right)$ have been investigated based on the results of "Jinhong" to find the appropriate concentration; it can be observed from Fig. 10c and $\mathrm{d}$ and the data details shown in Table S6 and S7 $\uparrow$ that the effect of 1-MCP/MCOD at low concentrations on the prevention of
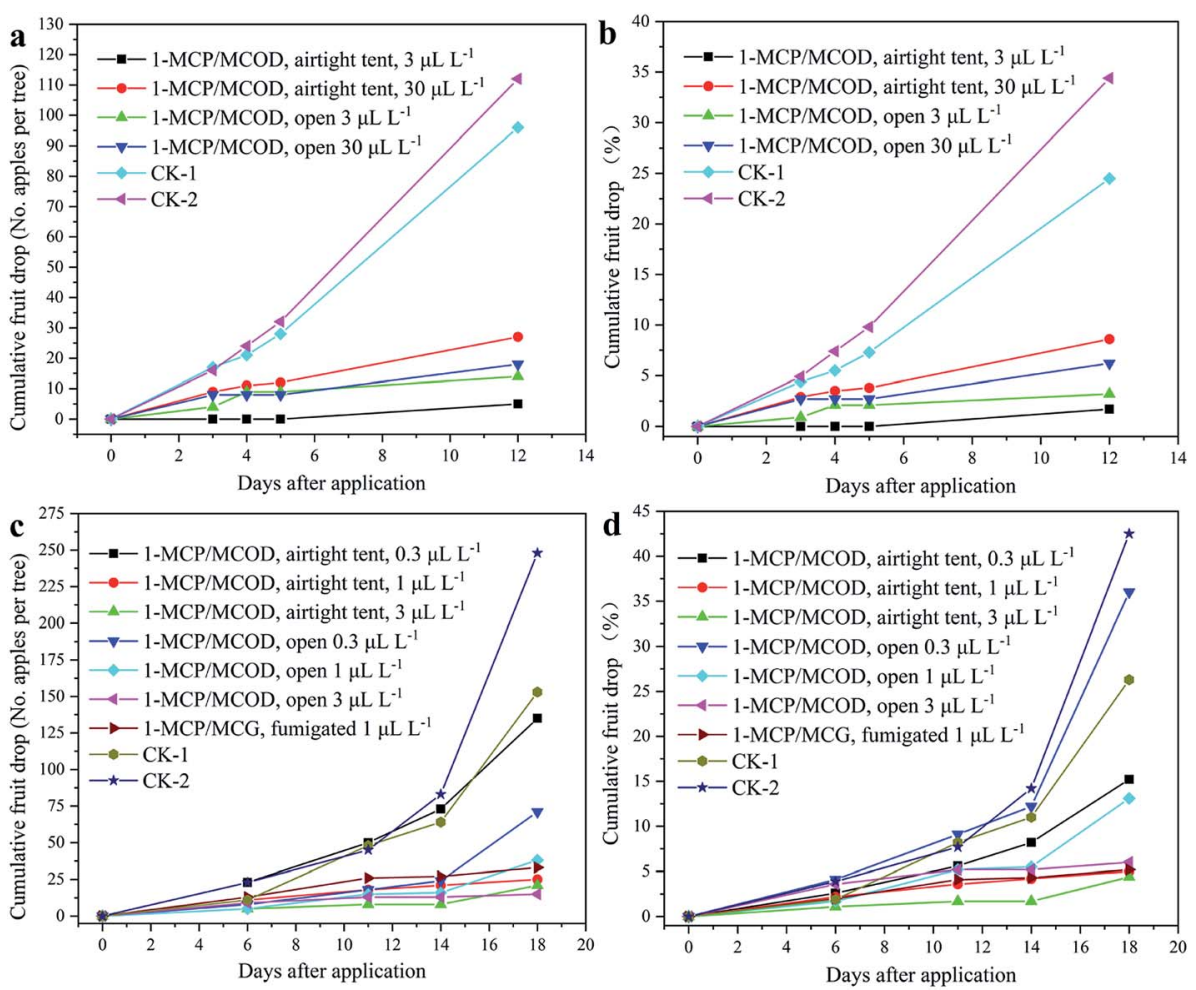

Fig. 11 Field images of the end date (for "Jinhong": (a) $C K$, (b) airtight $3 \mu L^{-1}$; for "Longfeng": (c) $C K$, and (d) airtight $3 \mu L L^{-1}$ ). 
fruit drop at the ripening stage is still obvious. Compared with the case of the untreated control, 1-MCP/MCOD at the two concentrations $1 \mu \mathrm{L} \mathrm{L}^{-1}$ and $3 \mu \mathrm{L} \mathrm{L}^{-1}$ could effectively prevent fruit drop under both airtight and open conditions; moreover, 1-MCP/MCOD at the very low concentration of $0.3 \mu \mathrm{L} \mathrm{L}^{-1}$ could slightly effectively prevent fruit drop under both airtight and open conditions. Compared with the commercial product 1MCP/MCG at $1 \mu \mathrm{L} \mathrm{L}^{-1}$ for fumigation, the efficacy of the 1MCP/MCOD formulation developed in this study was better at airtight $3 \mu \mathrm{L} \mathrm{L}^{-1}$ and airtight $1 \mu \mathrm{L} \mathrm{L}^{-1}$ and almost same at open $3 \mu \mathrm{L} \mathrm{L}^{-1}$. The eighteenth day was the harvest day. The order of effectiveness in preventing the fruit drop was airtight $3 \mu \mathrm{L} \mathrm{L}^{-1}>$ airtight $1 \mu \mathrm{L} \mathrm{L}^{-1}>$ fumigation $1 \mu \mathrm{L} \mathrm{L}^{-1}>$ open $3 \mu \mathrm{L} \mathrm{L}^{-1}>$ open 1 $\mu \mathrm{L} \mathrm{L}^{-1}>$ airtight $0.3 \mu \mathrm{L} \mathrm{L}^{-1}>$ open $0.3 \mu \mathrm{L} \mathrm{L}^{-1}$. The field images of the end date are shown in Fig. 11c and d. It could be observed that the fruit drop for "Longfeng" treated with airtight $1 \mu \mathrm{L} \mathrm{L}^{-1}$ $3 \mu \mathrm{L} \mathrm{L}^{-1}$ and open $3 \mu \mathrm{L} \mathrm{L}^{-1}$ were significantly less than that in the untreated case.

Therefore, the abovementioned results of "Jinhong" and "Longfeng" showed that it was not the higher concentration that showed a better effect. In maintaining fruit and vegetables quality, it is also not the higher concentration of 1-MCP, the better effect, which have been reported. ${ }^{49-51}$

\section{Conclusions}

In this study, a stable 1-MCP/MCOD was prepared. The tests of the emulsion stability and storage stability proved that it was a stable solid-liquid dispersion system. The release experiment proved that the formulation had controlled release characteristics, and the 1-MCP gas could stay at a higher concentration for more than 36 hours; this could make 1-MCP work continuously during the application. In further experiments, the deposition of the formulation on the plant tissues and its application in the open apple orchard showed that 1-MCP/ MCOD could prevent fruit drop effectively. These results not only supply a new 1-MCP/MCOD kind of formulation for the facile application of the 1-MCP gas in the open environment, but also show that the microcapsule oil dispersion formulation has great potential in gaseous pesticide applications.

\section{Conflicts of interest}

There are no conflicts to declare.

\section{Acknowledgements}

This project was supported by the National Key Research and Development Program of China (2017YFD0201300). We thank Dr Liying Wang of China Agricultural University for her experimental work about 1-MCP/MCG related to this project.

\section{References}

1 E. C. Sisler and M. Serek, Physiol. Plant., 1997, 100, 577-582.
2 L. Li, A. Lichter, D. Chalupowicz, D. Gamrasni, T. Goldberg, O. Nerya, R. Ben-Arie and R. Porat, Postharvest Biol. Technol., 2016, 111, 322-329.

3 J. Zhang, D. Cheng, B. Wang, I. Khan and Y. Ni, J. Agric. Food Chem., 2017, 65, 7308-7319.

4 B. Sun, F. Xu, X. Feng, H. Sun, Y. Wang, R. Ma and X. He, Food Science, 2014, 35, 303-313.

5 C. B. Watkins, Biotechnol. Adv., 2006, 24, 389-409.

6 B. C. In, J. Strable, B. M. Binder, T. G. Falbel and S. E. Patterson, Postharvest Biol. Technol., 2013, 86, 272-279.

7 J. Zhang, L. Zhu, S. Yu and Q. Jin, J. Plant Growth Regul., 2014, 33, 551-561.

8 E. C. Sisler and M. Serek, Plant Biol., 2003, 5, 473-480.

9 S. M. Blankenship and J. M. Dole, Postharvest Biol. Technol., 2003, 28, 1-25.

10 Q. Zhang, Z. Zhen, H. Jiang, X.-G. Li and J.-A. Liu, J. Agric. Food Chem., 2011, 59, 10539-10545.

11 B. Liu, Y. Wang, F. Yang, H. Cui and D. Wu, J. Agric. Food Chem., 2018, 66, 6561-6568.

12 B. Liu, Y. Wang, F. Yang, X. Wang, H. Shen, H. Cui and D. Wu, Colloids Surf., B, 2016, 144, 38-45.

13 D. Li, B. Liu, F. Yang, X. Wang, H. Shen and D. Wu, Carbohydr. Polym., 2016, 136, 341-349.

14 J. Feng, W. Yan, H. Xu and S. Zheng, Chin. J. Appl. Chem., 2010, 27, 82-86.

15 T. L. Neoh, K. Yamauchi, H. Yoshii and T. Furuta, J. Agric. Food Chem., 2007, 55, 11020-11026.

16 M. Serek, E. C. Sisler and H. Mibus, in Acta Horticulturae: X International Symposium on Postharvest Quality of Ornamental Plants, ed. A. C. R. Castro, F. L. Cuquel and V. Loges, International Society for Horticultural Science (ISHS), Porto de Galinhas, Pernambuco, Brazil, 2015, vol. 1060, pp. 23-29.

17 L. C. Argenta, X. Fan and J. P. Mattheis, HortScience, 2007, 42, 1651-1655.

18 J. R. DeEll, G. B. Lum and B. Ehsani-Moghaddam, Postharvest Biol. Technol., 2016, 111, 93-98.

19 A. Koukounaras and E. Sfakiotakis, Postharvest Biol. Technol., 2007, 46, 174-180.

20 J. Salazar, C. Jorquera, R. Campos-Vargas, C. Jorgensen, P. Zapata and R. Infante, Sci. Hortic., 2019, 244, 82-87.

21 D. Martinez-Romero, E. Dupille, F. Guillen, J. M. Valverde, M. Serrano and D. Valero, J. Agric. Food Chem., 2003, 51, 4680-4686.

22 G. A. Manganaris, A. R. Vicente, C. H. Crisosto and J. M. Labavitch, J. Agric. Food Chem., 2007, 55, 7015-7020.

23 N. Pongprasert and V. Srilaong, Postharvest Biol. Technol., 2014, 95, 42-45.

24 Y. Jiang and D. C. Joyce, Plant Growth Regul., 2003, 41, 225229.

25 M. E. C. Pereira, S. A. Sargent, C. A. Sims, D. J. Huber, J. H. Crane and J. K. Brecht, Postharvest Biol. Technol., 2014, 92, 121-127.

26 Z. Zhang, D. J. Huber and J. Rao, Postharvest Biol. Technol., 2011, 60, 83-91.

27 A. M. Opiyo and T.-J. Ying, Int. J. Food Sci. Technol., 2005, 40, 665-673. 
28 H. Su and W. D. Gubler, Postharvest Biol. Technol., 2012, 64, 133-137.

29 M. G. Villalobos-Acuna, W. V. Biasi, S. Flores, E. J. Mitcham, R. B. Elkins and N. H. Willits, HortScience, 2010, 45, 610-616.

30 D. C. Elfving, S. R. Drake, A. N. Reed and D. B. Visser, HortScience, 2007, 42, 1192-1199.

31 E. M. Kawakami, D. M. Oosterhuis, J. L. Snider and T. R. FitzSimons, Am. J. Plant Sci., 2013, 4, 1400-1408.

32 G. G. d. Brito, A. C. d. Ferreira, A. L. D. C. Borin and C. d. L. Morello, Cienc. Agrotecnol., 2013, 37, 9-16.

33 S. J. McArtney, J. D. Obermiller, J. R. Schupp, M. L. Parker and T. B. Edgington, HortScience, 2008, 43, 366-371.

34 H. Li and Q. Wang, Food Science, 2011, 32, 292-294.

35 S. Hussain, C. Zhong, Z. Bai, X. Cao, L. Zhu, A. Hussain, C. Zhu, S. Fahad, A. B. James, J. Zhang and Q. Jin, J. Plant Growth Regul., 2018, 37, 1368-1384.

36 E. M. Kawakami, D. M. Oosterhuis and J. L. Snider, J. Plant Growth Regul., 2010, 29, 280-288.

37 Z. E. Freiman, V. Rodov, Z. Yablovitz, B. Horev and M. A. Flaishman, Sci. Hortic., 2012, 138, 266-272.

38 V. Varanasi, S. Shin, F. Johnson, J. P. Mattheis and Y. Zhu, J. Plant Growth Regul., 2013, 32, 585-595.

39 C. B. Watkins, H. James, J. F. Nock, N. Reed and R. L. Oakes, in Acta Horticulturae: VI International Postharvest Symposium, ed. M. Erkan and U. Aksoy, International Society for
Horticultural Science (ISHS), Antalya, Turkey, 2010, vol. 877, pp. 365-374.

40 T. Ghosh, WIPO Pat., WO/2016/179251A1, 2016.

41 S. Gašić, D. Brkić and A. Tomašević, Pestic. Fitomed., 2011, 26, 409-413.

42 N. Hua, Mod. Agrochem., 2014, 13, 1-4.

43 N. Hua, Mod. Agrochem., 2014, 13, 1-5.

44 Z. Zhang and P. Zhang, Agrochemicals, 2016, 55, 391-395.

45 S. Zhang, Q. Wan, Y. Xing, J. Ding, S. Yang, W. Sun, M. Lu and B. Pan, AAPS PharmSciTech, 2019, 20, 75.

46 J. Feng, Q. Chen, X. Wu, S. M. Jafari and D. J. McClements, Environ. Sci. Pollut. Res., 2018, 25, 21742-21751.

$47 \mathrm{R}$. Yadav, Manual on development and use of FAO and WHO specifications for pesticides, FAO/WHO Joint Meeting on Pesticide Specifications (JMPS), Geneva and Rome, 2016.

48 R. Yuan and D. H. Carbaugh, HortScience, 2007, 42, 101-105. 49 H. P. V. Rupasinghe, D. P. Murr, G. Paliyath and L. Skog, J. Hortic. Sci. Biotechnol., 2000, 75, 271-276.

50 S. Lurie and A. Weksler, in Acta Horticulturae: V International Postharvest Symposium, ed. F. Mencarelli and P. Tonutti, International Society for Horticultural Science (ISHS), Verona, Italy, 2005, vol. 682, pp. 85-90.

51 J. Zhu, J. Feng and W. Yan, Northern Horticulture, 2010, 20, 195-198. 